OPEN ACCESS

Edited by:

Diego Gil,

Museo Nacional de Ciencias

Naturales (CSIC), Spain

Reviewed by:

Pierre J. Deviche,

Arizona State University, United States

Oscar Gordo,

Estación Biológica de Doñana (CSIC),

Spain

*Correspondence:

Adam M. Fudickar afudickar@gmail.com

Specialty section:

This article was submitted to Behavioral and Evolutionary Ecology,

a section of the journal

Frontiers in Ecology and Evolution

Received: 31 January 2017 Accepted: 12 July 2017 Published: 02 August 2017

Citation:

Fudickar AM, Greives TJ, Abolins-Abols M, Atwell JW, Meddle SL, Friis G, Stricker CA and Ketterson ED (2017) Mechanisms Associated with an Advance in the Timing of Seasonal Reproduction in an Urban Songbird.

Front. Ecol. Evol. 5:85. doi: 10.3389/fevo.2017.00085

\section{Mechanisms Associated with an Advance in the Timing of Seasonal Reproduction in an Urban Songbird}

\author{
Adam M. Fudickar ${ }^{1 *}$, Timothy J. Greives ${ }^{2}$, Mikus Abolins-Abols ${ }^{1}$, Jonathan W. Atwell ${ }^{1}$, \\ Simone L. Meddle ${ }^{3}$, Guillermo Friis ${ }^{4}$, Craig A. Stricker ${ }^{5}$ and Ellen D. Ketterson ${ }^{1}$ \\ ${ }^{1}$ Department of Biology, Indiana University, Bloomington, IN, United States, ${ }^{2}$ Department of Biological Sciences and \\ Environmental and Conservation Sciences Program, North Dakota State University, Fargo, ND, United States, ${ }^{3}$ The Roslin \\ Institute, The Royal (Dick) School of Veterinary Studies, The University of Edinburgh, Midlothian, United Kingdom, ${ }^{4}$ Museo \\ Nacional de Ciencias Naturales (CSIC), Madrid, Spain, ${ }^{5}$ Fort Collins Science Center, US Geological Survey, Fort Collins, CO, \\ United States
}

The colonization of urban environments by animals is often accompanied by earlier breeding and associated changes in seasonal schedules. Accelerated timing of seasonal reproduction in derived urban populations is a potential cause of evolutionary divergence from ancestral populations if differences in physiological processes that regulate reproductive timing become fixed over time. We compared reproductive development in free-living and captive male dark-eyed juncos deriving from a population that recently colonized a city ( $\sim 35$ years) and ceased migrating to that of conspecifics that live in sympatry with the urban population during winter and spring but migrate elsewhere to breed. We predicted that the earlier breeding sedentary urban birds would exhibit accelerated reproductive development in the spring along the hypothalamic-pituitary-gonadal (HPG) axis as compared to migrants. We found that free-living sedentary urban and migrant juncos differed at the level of the pituitary when measured as baseline luteinizing hormone (LH) levels, but not in increased $\mathrm{LH}$ when challenged with Gonadotropin-Releasing Hormone $(\mathrm{GnRH})$. Among captives held in a common garden, and at the level of the gonad, we found that sedentary urban birds produced more testosterone in response to $\mathrm{GnRH}$ than migrants living in the same common environment, suggesting greater gonadal sensitivity in the derived urban population. Greater gonadal sensitivity could arise from greater upstream activation by LH or FSH or from reduced suppression of gonadal development by the adrenal axis. We compared abundance of gonadal transcripts for $\mathrm{LH}$ receptor (LHR), follicle stimulating hormone receptor (FSHR), glucocorticoid receptor (GR), and mineralocorticoid receptor (MR) in the common-garden, predicting either more abundant transcripts for LHR and FSHR or fewer transcripts for GR and MR in the earlier breeding sedentary urban breeders, as compared to the migrants. We found no difference in the expression of these genes. Together these data suggest that advanced timing of reproduction in a recently derived urban population is facilitated by earlier increase in upstream baseline activity of the HPG and earlier release from gonadal suppression 
by yet-to-be-discovered mechanisms. Evolutionarily, our results suggest that potential for gene flow between seasonally sympatric populations may be limited due to urban-induced advances in the timing of reproduction and resulting allochrony with ancestral forms.

Keywords: seasonal breeding, phenology, supplemental cues, photoperiod, migration, songbird, gonads, urbanization

\section{INTRODUCTION}

Over the past several centuries, urban landscapes have replaced native habitat in many parts of the world (Marzluff, 2016; Alberti et al., 2017). Urban environments can differ from the environments they replace in many ways, and while human activity in urban areas can pose novel challenges to animals (Shanahan et al., 2014), relatively mild urban microclimates and enhanced resource availability can also lead to increased opportunities to reproduce (Deviche and Davies, 2013).

A common observation is that urban bird populations begin their breeding season earlier compared to rural populations (Deviche and Davies, 2013). Seasonal fluctuations in climate and resource availability are often reduced in urban environments, which can lead to longer breeding seasons and year-round occupancy by formerly migratory lineages (Adriaensen and Dhondt, 1990; Partecke and Gwinner, 2007; Chamberlain et al., 2009; Atwell et al., 2014). If the physiological processes that lead to differences between urban and rural populations in reproductive timing and other seasonal traits become fixed over time, then gene flow and interbreeding could be limited (Evans et al., 2010; Fudickar et al., 2016a).

Though it is clear that urbanization can advance timing of reproduction, relatively little is known about the sources of variation in reproductive physiology that modulate the advancement or extension of breeding. The hypothalamicpituitary-gonadal (HPG) axis plays a central role in the seasonal regulation of reproduction in birds (Dawson, 2015; Figure 1). The timing and rate of the seasonal activation of the HPG is modulated by a combination of predictive (day length) and supplementary cues (e.g., food and temperature; Hahn et al., 2005; Schaper et al., 2012; Wingfield et al., 2012; Dawson, 2015; Watts et al., 2015). Advancement in breeding phenology in urban habitats, therefore, may result from a plastic response to the novel habitat by phenotypically flexible individuals and/or a genetic response to selection for earlier seasonal activation of the HPG. Whether or not differences in timing are fixed or flexible may have important evolutionary implications. For example, if advanced reproduction in urban populations is the result of selection for greater sensitivity of the HPG at shorter day lengths-either by an earlier seasonal response or responding at a faster rate-then the resulting reproductive allochrony (asynchronous reproduction) may limit gene flow between urban and rural populations, ultimately leading to selection against hybrids. Alternatively, if advanced timing in urban populations is modulated by plastic responses, then the scope for divergence

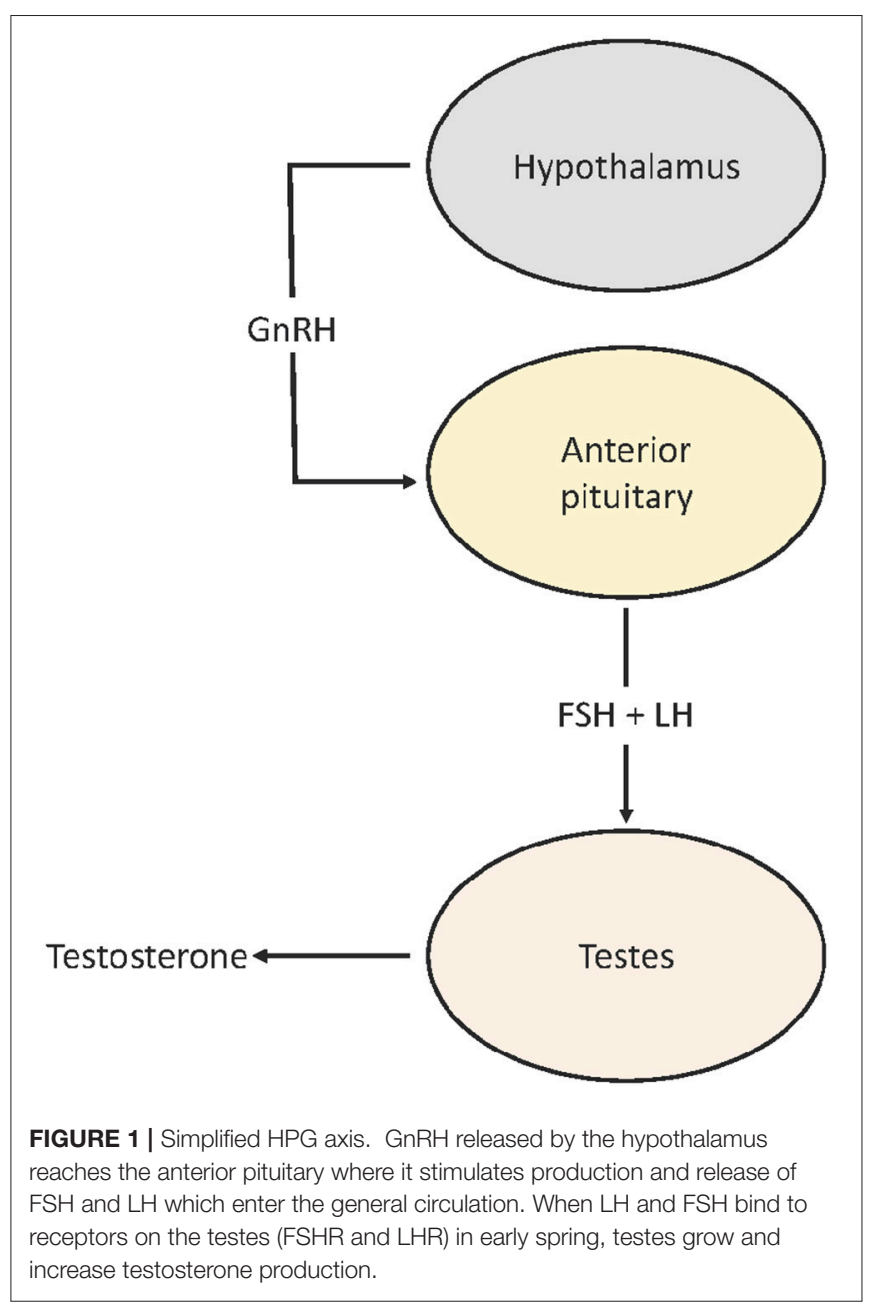

may be limited, as immigrants would be capable of adopting the timing of established urban populations. These alternatives also have important implications for the adaptability of both urban and rural populations to cope with future environmental change.

To date, there is limited evidence from studies that have compared the endocrine axes of urban vs. nearby rural populations in both field and common garden settings to support the importance of both plasticity and genetics in modulating earlier reproduction and HPG activation in urban habitats (Partecke et al., 2004, 2006; Schoech, 2009; Atwell et al., 2014; Davies et al., 2015). While these studies highlight the importance of differential HPG activity in facilitating earlier and extended breeding in urban habitats, much remains to be learned about 
the generality of those results, as well as the specific mechanistic sources of variation across the many "levels" of the HPG axis. Additionally, one interpretive challenge with such prior studies is that they typically sample putatively related populations that inhabit nearby yet radically different urban vs. rural habitats during the sampling period. In our study, we utilized both field and common garden settings to probe multiple levels of HPG activity in both urban-breeding and migratory nonresident populations during a critical life-history stage in which they co-occur in urban habitats, yet pursue divergent seasonal strategies.

Heteropatry-where closely related populations coexist during the non-breeding season (e.g., fall, winter, and /or early spring) yet pursue independent phenological and geographical trajectories during breeding-provides a unique opportunity to address the physiological mechanisms that underlie reproductive timing differences between populations (Winker, 2010; Ketterson et al., 2015; Bauer et al., 2016; Fudickar et al., 2016a,b; Greives et al., 2016; Ramenofsky et al., 2017). Broadly distributed avian species often have heteropatric distributions, in which some populations migrate while others do not (Winker, 2010). Despite experiencing the same photoperiodic and supplementary cues for much of the annual cycle (e.g., from the time that migrants arrive in the fall until they depart in the spring), there is often distinct phenological divergence in spring, when sedentary individuals transition into breeding, while migrants delay reproduction and prepare for and complete a migration before breeding. As a result, closely related sedentary and migratory birds are effectively sympatric during the nonbreeding season as well as the transitional periods between non-breeding and breeding, yet are entirely allopatric during the core breeding season. In the current study, we compared specific neuroendocrine mechanisms predicted to underlie reproductive timing differences between a recently established ( $\sim 35$ years $)$ urban population of juncos vs. heteropatric ancestral migrant juncos, under both free-living (field) and common-garden (captive) conditions.

This study focused on a population of dark-eyed juncos ( $J$. hyemalis thurberi) that became established in urban San Diego CA USA in the early 1980s, likely as a result of overwintering migratory birds remaining to breed (Rasner et al., 2004; Yeh, 2004; Atwell et al., 2012, 2014). Since then, an isolated sedentary urban breeding population has persisted with limited subsequent immigration despite a sympatric distribution with migratory juncos between October and April (Yeh and Price, 2004; Unitt, 2005). The colonization event and current heteropatric distribution thus provides a unique opportunity to examine mechanisms associated with contemporary adaptation to an urban environment. Although the precise breeding location of the migrants is not known, previous studies have shown that first egg laying dates in the San Diego population are $\sim 2.5$ months earlier than the closest non-urban populations (Yeh and Price, 2004; Atwell et al., 2014). A recent study, in which juncos from San Diego and the closest non-urban breeding population $(\sim 50 \mathrm{~km})$ were captured on their respective breeding grounds as juveniles and observed in a commongarden experiment, found that population differences in the seasonal timing of mean peak HPG activity (plasma testosterone and post Gonadotropin-Releasing Hormone $(\mathrm{GnRH})$ challenge testosterone) observed in the wild did not persist in the common garden (Atwell et al., 2014), which suggests a degree of flexibility in reproductive timing in both populations.

Here, we asked whether differences in the timing of the seasonal onset of reproduction between heteropatric sedentary urban and migratory juncos result from differential activation of the HPG in early spring and whether any difference is linked to differences in sensitivity to day length. While Atwell et al. (2014) compared the duration and peak timing of HPG activity of sedentary urban juncos from San Diego with that of the closest non-urban population, in the current study we focused on a comparison of sedentary urban breeders with migrants that are sympatric during winter and early spring. Based on previous reports indicating that winter flocks of juncos consist of migrants from a range of breeding populations (Fudickar et al., 2016a; J. Atwell personal observations), we expected that migrant juncos in San Diego would originate from multiple breeding populations.

First, we compared free-living sedentary urban and migratory juncos on their shared overwintering grounds in February for responsiveness of the HPG endocrine axis-specifically the response of the pituitary gland to repeated GnRH stimulation. By repeatedly injecting birds with GnRH, our aim was to more accurately replicate the pulsatile nature of $\mathrm{GnRH}$ that occurs naturally in spring. By measuring luteinizing hormone (LH) following repeated injections of $\mathrm{GnRH}$, we assessed the potential for variation in pituitary sensitivity to modulate differential HPG axis activity in resident vs. migrant cohorts during the period when their observed seasonal strategies diverge, despite exposure to identical environmental conditions. We have previously demonstrated in longer diverged ( $\sim 15,000$ years) overwintering juncos that pituitary sensitivity to repeated GnRH injection may serve to functionally limit HPG axis activation in female, but not male migrants (Greives et al., 2016). The hypothesis to be tested here was whether migrant birds have a weaker response to GnRH as would be predicted if reduced pituitary sensitivity to repeated GnRH acts as a mechanism to delay reproduction in birds that will forego breeding in the urban environment and migrate prior to reproduction.

Next, we measured morphological and physiological correlates of reproductive development across 4 weeks in early spring in sedentary urban and migrant junco males held in a captive common-garden experiment that simulated natural photoperiod (during the same early spring period), and provided ad libitum food, mild temperatures, and reduced social interactions. If the seasonal timing of reproduction in sedentary urban juncos is advanced due to increased sensitivity to photoperiodic cues in early spring, we predicted that timing of gonadal development and endocrine profiles of urban-breeding and migrant juncos should remain divergent. In contrast, if the seasonal timing of reproduction differs in sedentary urban and migrant juncos due to flexible responses to the environment, we predicted convergence of seasonal timing of gonadal development and endocrine profiles in captivity. We limited our study to male juncos because, in captivity, females do 
not advance into reproduction in the spring as readily as males (E.K., personal observation).

Finally, we compared gonadal transcript abundance of $\mathrm{LH}$ receptor (LHR), follicle stimulating hormone receptor (FSHR), glucocorticoid receptor (GR), and mineralocorticoid receptor (MR) of sedentary urban and migrant juncos in early spring. LHR and FSHR are important for seasonal gonadal growth in birds, and GR and MR can suppress gonadal growth and activation in birds (McGuire et al., 2013; Blas, 2015; Vizcarra et al., 2015). Therefore, we predicted higher LHR and FSHR transcript abundance in sedentary urban juncos in early spring and higher GR and/or MR transcript abundance in migrant juncos in early spring.

We interpret our collective results in the context of both the proximate mechanisms underlying phenotypic divergence in reproductive timing, as well as the ultimate factors and evolutionary implications associated with the observed physiological divergences and convergences.

\section{METHODS}

\section{Field Study}

\section{Capture and Morphological Measures}

Thirty-seven male juncos were captured in the urban habitat of the University of California-San Diego (UCSD) campus in La Jolla, California, USA, using continuously monitored walk-in traps baited with seed. Birds in the field study were classified post hoc as sedentary urban breeders or migrants using a combination of morphological measures and stable isotopes in feather tissue (hydrogen; details below). We collected the outermost secondary feather from each bird's right wing during handling to examine stable hydrogen $\left(\delta^{2} \mathrm{H}\right)$ signatures. Using calipers, we measured the length of the right tarsus $( \pm 0.1 \mathrm{~mm})$. Using a ruler, we measured the length of the right wing (flattened) and the tail $( \pm 0.5 \mathrm{~mm})$. Previous studies have reported that juncos that breed in San Diego have reduced white on their tail feathers and black on their heads compared to rural migratory populations (Yeh, 2004; Atwell et al., 2014). We visually estimated the percentage of white in the four outermost right tail feathers of each bird at capture. Using calipers, we measured (a) the length of the entire hood from the bill to the ventral terminus and (b) the length from the bill to the ventral terminus of homogenous black feathers. Age class was determined based on wing plumage as juncos have a limited first prebasic molt, making it possible to distinguish between first-year and after-first-year birds (Nolan, 2002). Capture dates were from 13 February to 23 February 2014, $\sim 4$ weeks prior to the historical first egg date in the resident population, and roughly 2-3 weeks prior to the apparent peak of migrant passage through southern California (J.W. Atwell personal observation). All individuals received a unique numbered metal band to avoid repeat sampling. All procedures were approved by the Indiana University, North Dakota State University, and University of California San Diego Institutional Animal Care and Use Committees and conducted under appropriate federal banding permits (permit \#20261) and the California Department of Fish and Wildlife (permit \#007852).

\section{Blood Sample Collection-Field}

Immediately after capture, a $50 \mu \mathrm{l}$ blood sample was obtained from the alar wing vein for baseline measures of LH. The birds then received an intramuscular injection of $1.25 \mu \mathrm{g}$ chicken GnRH (American Peptide, Sunnyvale, CA) in $50 \mu$ l of phosphatebuffered saline into the pectoralis muscle. This dose fully activates the HPG axis in this species (Jawor et al., 2006). Five minutes following the first GnRH injection, a second $50 \mu$ l blood sample was taken from the wing vein for LH. Previous work in this species and white-crowned sparrows (Zonotrichia leucophrys gambelii) indicated $\mathrm{LH}$ levels reach a peak $5 \mathrm{~min}$ following injection and then significantly decline by $20 \mathrm{~min}$ and return to baseline at $30 \mathrm{~min}$ (Wingfield et al., 1979; Bergeon Burns et al., 2014). The birds then received a second injection of GnRH (same dose as above) $30 \mathrm{~min}$ after the first injection, followed by a third injection of $\mathrm{GnRH}$ (same dose as above) $30 \mathrm{~min}$ following the second injection. A final $50 \mu \mathrm{l}$ blood sample was collected 5 min following the third injection of GnRH (65 min after the first GnRH injection). All birds were held in an opaque paper bag between injections. Blood samples were stored on ice until later processing in the laboratory. Samples were centrifuged to separate red blood cells from plasma. Plasma was collected with a Hamilton syringe and stored at $-20^{\circ} \mathrm{C}$ until it was shipped on dry ice to The Roslin Institute, The University of Edinburgh for LH quantification.

\section{Luteinizing Hormone Assay}

To determine plasma LH, we used a micromodification of the radioimmunoassay described previously (Sharp et al., 1987). Briefly, the assay reaction volume was $60 \mu \mathrm{l}$, comprised of 20 $\mu l$ of plasma sample or standard, $20 \mu \mathrm{l}$ of primary rabbit $\mathrm{LH}$ antibody, and $20 \mu \mathrm{l}$ of $\mathrm{I}^{125}$-labeled LH. The primary antibody was precipitated to separate free and bound $\mathrm{I}^{125}$ label using 20 $\mu l$ of donkey anti-rabbit precipitating serum and $20 \mu \mathrm{l}$ of nonimmune rabbit serum. All samples were measured in duplicate in a single assay. The intra-assay coefficient of variation was $2.9 \%$ and the minimum detectable dose was $0.2 \mathrm{ng} / \mathrm{ml}$. This LH radioimmunoassay has been used extensively in many avian species including dark-eyed juncos (Deviche et al., 2000; Meddle et al., 2002; Wingfield et al., 2012; Bergeon Burns et al., 2014; Greives et al., 2016).

\section{Common Garden Study Bird Capture and Housing}

From December 13 to 18, 2014 we captured 30 male juncos (population of origin classification details described above) from the UCSD campus using baited walk-in traps. After capture, we collected the outermost secondary feather from each bird's right wing and measured plumage and morphological traits as we did for the field study for post hoc classification of sedentary urban and migrant individuals. We housed all birds for 1-6 days (depending on capture date) in cages in an indoor facility with natural sunlight, where they were provided food (2:1 mixture of white millet and cracked corn) and water ad libitum. On December 19, 2014 the birds were transported overnight by air to Indiana University. At Indiana University, all birds were held together in a climate controlled free flight aviary $(6.4 \times 3.2$ 
$\times 2.4 \mathrm{~m})$ and were provided with water containing Nekton-S Multi-Vitamin for Birds (Arcata Pet, Arcata, CA) and food ad libitum. Birds were fed a seed mix containing white millet and sunflower chips (2:1), live mealworms, orange slices, and a soft diet containing ground puppy chow, hard-boiled eggs, and carrots. We adjusted lights in the aviary every $3 \pm 1$ days to simulate the natural seasonal changes in day length in San Diego. Throughout the experiment, the temperature in the aviary was maintained at $16 \pm 2{ }^{\circ} \mathrm{C}$.

On 29 January 2015, we individually housed the birds in $61 \times 46 \times 46-\mathrm{cm}$ cages and separated them into 5 identical indoor aviary rooms $(2.5 \times 2.1 \times 2.4 \mathrm{~m})$. In each room, we arranged cages so that birds were visually isolated from each other. All procedures were approved by the Indiana University and University of California San Diego Institutional Animal Care and Use Committees and conducted under appropriate scientific collecting permits issued by the USFWS (permit \#MB093279) and the California Department of Fish and Wildlife (permit $\# 007852)$.

\section{Blood Sample Collection-Captivity}

We collected blood samples $(\sim 150 \mu \mathrm{l})$ from each bird every 6 or 7 days from February 26 to March 202015 to measure baseline plasma corticosterone (CORT), initial plasma testosterone, and plasma testosterone in response to a standardized $\mathrm{GnRH}$ challenge protocol (testosterone post$\mathrm{GnRH}$ ). The GnRH challenge protocol involves collecting a blood sample 30 min after an intramuscular injection of $\mathrm{GnRH}$, which is administered following the initial blood sample. This assay allows for a robust and repeatable measure of an individual male's ability to produce testosterone in response to a standardized physiological stimulus and is known to vary seasonally in relation to reproductive development in juncos (Jawor et al., 2006). Blood samples for CORT were always collected within $3 \mathrm{~min}$ of entering a room (range $=1 \mathrm{~min} 30 \mathrm{~s}$ to $3 \mathrm{~min}$; average $=2 \mathrm{~min} 41 \mathrm{~s}$ ), and rooms were entered only once per sampling day. Blood samples for plasma testosterone were collected immediately following sampling for CORT and were always taken within $5 \mathrm{~min}$ of entering a room. Exactly $5 \mathrm{~min}$ after entering a room, we injected birds with $1.25 \mu \mathrm{g}$ chicken GnRH (American Peptide, Sunnyvale, CA) in $50 \mu \mathrm{l}$ of phosphate-buffered saline. Thirty minutes after each injection, we collected a second blood sample $(\sim 75 \mu \mathrm{l})$ to assess an individual male's potential maximum testosterone. Samples were kept at $4^{\circ} \mathrm{C}$ until they were centrifuged (within 4 h). After centrifugation, we collected plasma using a Hamilton syringe, and plasma and red blood cells were frozen at $-20^{\circ} \mathrm{C}$ until they were assayed.

\section{Morphological Measurements}

Each sampling day, after the last blood sample was collected from an individual, we measured subcutaneous fat and cloacal protuberance volume. Fat varies seasonally in relation to transitions between both (1) wintering and breeding condition (reduced fat) and (2) wintering and pre-migratory condition (increased fat; Clark, 1979). Migration is a metabolically taxing behavior, and migrants use fat as the primary source of fuel during the migratory stage (Jenni and Jenni-Eiermann, 1998).
We visually estimated fat score (0-4) for subcutaneous fat deposition in furcular and abdominal regions separately as follows: $0=$ no fat present, $1=$ trace amounts, $2=$ half full, 3 $=$ full, and $4=$ bulging. We summed furcular and abdominal fat scores to obtain a total fat score (range 0-8; Fudickar et al., 2016a).

The cloacal protuberance (CP), the terminal part of the passerine ductus deferens, is the primary location of sperm storage, is testosterone sensitive and its seasonally variable size is a reliable measure of breeding condition in male passerines (Wolfson, 1952). Cloacal protuberance volume $(V)$ was estimated by using the formula to calculate the volume of a cylinder $\left[V=(\text { radius })^{2}\right.$ (height) $]$. Cloacal width (diameter, $\left.w, \pm 0.1 \mathrm{~mm}\right)$ was measured with dial calipers, and height $(h, \pm 0.5 \mathrm{~mm})$ was measured with a ruler, which allowed us to ensure that our measurement started flush against the body.

\section{Gonadal Development}

To investigate differences in the seasonal timing of gonadal development, at the end of the study (24-25 March 2015), we euthanized birds with an isoflurane overdose and dissected both testes, which were immediately flash frozen on dry ice and transferred to $-80^{\circ} \mathrm{C}$, where they were stored until they were weighed and we extracted mRNA. To compare testis size among individuals, we measured frozen testis mass of one testis from each bird in the lab using a digital microbalance accurate to $\pm 0.001 \mathrm{~g}$.

\section{Corticosterone and Testosterone Assays}

Following established methods for juncos (Jawor et al., 2006), we determined plasma CORT and testosterone concentrations from 10 to $20 \mu \mathrm{l}$ aliquots, respectively, after a diethyl-ether extraction of steroids using enzyme immunoassays (CORT: 500655, Cayman Chemical; testosterone: ADI-900-065, Enzo Life Sciences). Coefficients of variation of the assays were as follows: CORT: $n=4$ plates, intraplate $=5.55 \pm 1.8 \%$ (mean \pm SE), range $=0.22-7.71 \%$; testosterone: $n=8$ plates, intraplate $=8.59 \pm$ $0.8 \%$ (mean $\pm \mathrm{SE}$ ), range $=5.45-10.85 \%$. Sampling dates were assigned equally across plates.

\section{mRNA Extraction and qPCR}

Total RNA was extracted from one testis for each bird using the Trizol method (Invitrogen, Carlsbad, CA). Following spectrophotometry to quantify total RNA, $1 \mu \mathrm{g}$ RNA was treated with DNAse (Promega, Madison, WI) and underwent reversetranscription PCR using oligo dT primers and Superscript III reverse transcriptase (Invitrogen, Carlsbad, CA). The resulting CDNA was used as a template for quantitative real-time PCR (qPCR) to measure gene expression of LH receptor (LHR), FSH receptor (FSHR), glucocorticoid receptor (GR), and mineralcorticoid receptor (MR). qPCR reactions were run on a Stratagene MX3000P using PerfeCTa SYBR Green SuperMix (low ROX, Quanta Biosciences, Gaithersburg, MD, USA). We used MxPro software (v.4.10, Agilent, Santa Clara, CA, USA) to analyze gene expression with the comparative Ct method, where abundance of transcripts from individual samples is expressed against a calibrator sample, and normalized against expression 
of a housekeeping gene (RPL4). RPL4 is one of the most stable housekeeping genes in testes of passerines (Zinzow-Kramer et al., 2014), and its expression did not differ between the sedentary urban and migrant juncos in our study (Mann-Whitney $U=$ $32.50, n_{\text {urban }}=19, n_{\text {migrant }}=6, p=0.234$ two-tailed). Primer sequences are reported in the Supplementary Material.

\section{DNA Extraction}

Genomic DNA (gDNA) was extracted from red blood cells in the Center for the Integrative Study of Animal Behavior (CISAB) at Indiana University, using IBI Scientific MINI Genomic DNA kits (IB46701). Red blood cells collected during the captive study were used for the DNA extractions. DNA was measured with a Nanodrop spectrophotometer (Take 3).

\section{Feather isotopes}

The outermost (distal) secondary feather from each bird's right wing was collected during handling to examine stable hydrogen isotope $\left(\delta^{2} \mathrm{H}\right)$ signatures. Juncos complete their annual molt cycle before leaving breeding habitats, or retain juvenile wing feathers throughout their first annual cycle (Nolan, 2002). $\delta^{2} \mathrm{H}$ of these feathers therefore can, in some cases, permit assignment of breeding latitude based on known patterns of isotopic variation in precipitation (Bowen et al., 2005). Feathers were cleaned of oils using a 2:1 chloroform: methanol solution and allowed to air-dry under a fume hood at Indiana University. Approximately $0.50 \mathrm{mg}$ of vane material was clipped from the proximal end of each feather and loaded into $3 \times 5 \mathrm{~mm}$ pressed silver capsules. The non-exchangeable hydrogen isotope composition was measured by continuous flow isotope ratio mass spectrometry using a Finnigan TC/EA interfaced to a Finnigan DeltaPlus XL mass spectrometer (Thermo Scientific, Bremen, Germany), using established methods at the U.S. Geological Survey Stable Isotope Laboratory in Denver, Colorado (Wunder et al., 2012). $\delta^{2} \mathrm{H}$ values are reported in per mil notation (\%) relative to $\mathrm{V}$ SMOW, using internal standards ( -78 and $-172 \%$, respectively) calibrated to CFS-CHS-BWB (Wassenaar and Hobson, 2003). Benzoic acid $\left(\delta^{2} \mathrm{H}=-61 \%\right)$ and IAEA-CH-7 $\left(\delta^{2} \mathrm{H}=-100 \%\right.$ ) were also analyzed within analytical sequences with a precision of $< \pm 4 \%$.

\section{Genotyping-by-sequencing}

We took advantage of the genomic data generated in a study running in parallel to the study reported here to confirm the genetic identity of the UCSD resident population as a differentiated group from migrant populations of Junco hyemalis thurberi of California. To do so, we used genotyping-bysequencing (GBS, Elshire et al., 2011) to obtain the genotypes of $43 \mathrm{~J}$. hyemalis thurberi sampled in the UCSD campus. 32 of these 43 samples were collected at the time of the captive study (30 birds held in the captive study and 2 additional birds caught at the same time) and 11 were collected during previous studies from known breeders at UCSD. Fifty additional samples were collected from individuals from surrounding migratory populations of Junco hyemalis thurberi from California. Specific sampled populations were (sample sizes in parenthesis): UCSD campus (43), Mount Laguna (12), Palomares (7), San Jacinto (8),
Santa Barbara (7), Eldorado (8) and Mendocino (8). GBS libraries were prepared and sequenced at Cornell University's Institute for Genomic Diversity, using the restriction enzyme PstI for digestion. Sequencing was carried out in an Illumina HiSeq 2000 platform and resulting reads were trimmed and quality filtered with PRINSEQ (Schmieder and Edwards, 2011). We used the Genome Analysis Toolkit (GATK, McKenna et al., 2010) version 3.6-0 to perform the variant calling after mapping the reads against a Junco draft genome assembled for this purpose with the Burrows-Wheeler Aligner (BWA, Li and Durbin, 2009). We then used VCFTOOLS (Danecek et al., 2011) to retain only highly confident biallelic single nucleotide polymorphisms (SNPs) with a genotyping quality phred score over 70, a minimum allele frequency of $1.5 \%$ and per site missing rate lower than $10 \%$. We also implemented a threshold for SNPs showing highly significant deviations from Hardy-Weinberg equilibrium (HWE) with a $p$ value of $10^{-4}$ to filter out false variants arising from the alignment of paralogous loci. The resulting SNP matrix was further filtered to exclude variants potentially under selection with BayeScan (Foll and Gaggiotti, 2008) and for linkage disequilibrium using the package SNPrelate (Zheng, 2012) in R (R_Core_Team, 2015) version 3.2.2 for a final dataset of 23,051 SNPs.

\section{Captive study classification}

Using the 23,051 SNP matrix, we ran a STRUCTURE (Pritchard et al., 2000) analysis for two populations $(K=2)$ to test for differentiation between UCSD residents and the remaining populations of Californian juncos. We ran the analysis five times after running a preliminary analysis to infer the lambda value. The burning was set to $50 \mathrm{~K}$ iterations and the analysis ran for an additional $100 \mathrm{~K}$ iterations. Two main clusters were identified in all five runs, clearly consistent with a resident group of UCSD breeders and a second cluster encompassing the remaining populations. From the 43 individuals sampled on the UCSD campus, we could confidently assign 37 individuals (those with a posterior assignation probability to either group over 0.9 ): 8 were clear migrants, 6 of which were collected for the captive study (posterior assignment probability to the UCSD breeders group $=0$ ), while the other 29 were clear residents, 19 of which were collected for the captive study (posterior assignment to the UCSD breeders group ranging from 0.93 to 1 ). The remaining 6 individuals presented different degrees of admixture, 3 of which were collected for the captive study (posterior assignment to the UCSD breeders group ranging from 0.14 to 0.81 ). Due to uncertainty in their classification, the 3 individuals were excluded in our comparisons. We were not able to classify 2 additional birds captured for the captive study due to insufficient DNA quality. Final sample size for the captive comparison was 19 sedentary urban birds and 6 migrants. A plot of the STRUCTURE analysis is included in the Supplementary Material.

\section{Field study classification}

We did not have genomic data to classify birds used in the field study. To classify birds from the field study, we first ran a discriminant function analysis (DFA) using the morphologic and isotopic data from the birds held in the captive study that were confidently classified individuals based on genomic data 
(described above). Next, we used the DFA model generated from genotyped birds to classify 35 UCSD campus individuals for which we had morphometric and isotope data but not genomic data, including them as blind cases in the model construction. To inform the DFA model, we used isotope and morphometric data from genotyped birds with sufficient isotope and morphometric data ( $N=25,6$ migrants and 19 residents from the captive study) to run a DFA in SPSS 22 (SPSS Inc. 2008, Chicago, IL, USA) for the two groups based on (i) the isotopic scores of hydrogen; (ii) the length of the tarsus, the wing and the tail; (iii) the percentage of white in the right tail feather 1,2,3, and 4; and (iv), the distance from the front of the crown to where the black ends, the distance from the front of the crown to the very back and the percent of the crown that is black (discriminant function coefficients are reported in the Supplementary Material). Because of the relatively low overall and per group sample size, we included in the analysis a "leave-one-out" cross validation test to assess the power of our model to correctly classify individuals. The validation test correctly classified five of the six migrant individuals (an $83.3 \%$ of migrants correctly classified) and 17 of 19 residents (an 89.5\% of residents correctly classified), yielding a total of $88 \%$ of cases correctly classified.

Finally, we used the DFA model to classify the 35 UCSD campus individuals for which we had morphometric and isotope scores but not genomic data, including them as blind cases in the model construction. The predicted group membership resulted in 9 migrants (probability of group membership ranging from 0.96 to 1 ) and 26 residents (probability of group membership ranging from 0.98 to 1 ). In light of the cross validation test, these outcomes should be taken with caution. Two additional birds in the field study were captured the following winter for the captive study, and therefore were genotyped (both migrants). The final sample size of our comparison of free-living birds was 11 migrants and 26 residents.

\section{Statistical Analyses of Hormone and Physiology Data}

We used non-parametric statistical tests for all physiological measures, due to unequal sample sizes and unequal variances in both the field and captive studies.

\section{Field study}

Age distribution was equal in sedentary urban and migrant juncos sampled for $\mathrm{LH}$ in the field (Fisher's exact test, $P=$ 0.443 ; first-year sedentary urban $=7$, after-first-year sedentary urban $=19$, first-year migrant $=5$, after-first-year migrant $=6$ ) . To test for within-subject variance in plasma LH levels across the three sample times (baseline LH, LH 5 min after a single $\mathrm{GnRH}$ injection, and $5 \mathrm{~min}$ after the final GnRH injection), we used a Friedman test with sedentary urban and migrant juncos combined. We used Mann-Whitney $U$ test to test for betweengroup differences in $\mathrm{LH}$ at each sample time.

\section{Captive study}

Age distribution was equal in sedentary urban and migrant juncos held in the captive study (Fisher's exact test, $P=0.630$; first-year sedentary urban $=6$, after-first-year sedentary urban $=13$, first-year migrant $=3$, after-first-year migrant $=3$ ). To test for within-subject variance in physiological measures (cloacal protuberance volume, plasma testosterone, testosterone postGnRH challenge, subcutaneous fat score, and CORT) across the four sampling weeks, we used a Friedman test for each week with sedentary urban and migrant juncos combined. We used a Mann-Whitney $U$ test to test for between-group differences in physiological measures each week. We were not able to sample enough plasma from all birds at each time point, therefore, sample numbers vary across sampling times. To test for differences between sedentary urban and migrant juncos in gonadal FSHR, GR, LHR, and MR transcript abundance, we used independent Mann-Whitney U tests. We performed all statistical analyses using SPSS, version 24 (IBM). All reported $p$-values are two-tailed.

\section{RESULTS}

\section{Field Study}

\section{Luteinizing Hormone}

Sedentary urban juncos had higher baseline LH than migrant juncos $\left(U=48.50, n_{\text {urban }}=26, n_{\text {migrant }}=11, p=0.002\right) . \mathrm{LH}$ increased after injection $\left(n=32\right.$, Chi-Square $\chi^{2}=39.44$, $\mathrm{df}=$ $2, p<0.001)$, but there was no difference between the groups following GnRH challenge (LH 5 min: $U=106.00, n_{\text {urban }}=25$, $n_{\text {migrant }}=10, p=0.488$; LH 65 min: $U=107.50, n_{\text {urban }}=24$, $\left.n_{\text {migrant }}=10, p=0.637\right)$ (Figure 2).

\section{Common Garden Study Gonads}

At the end of the 4-week sampling period, sedentary urban juncos had larger gonads than migrant juncos $\left(U=18.00, n_{\text {urban }}=\right.$

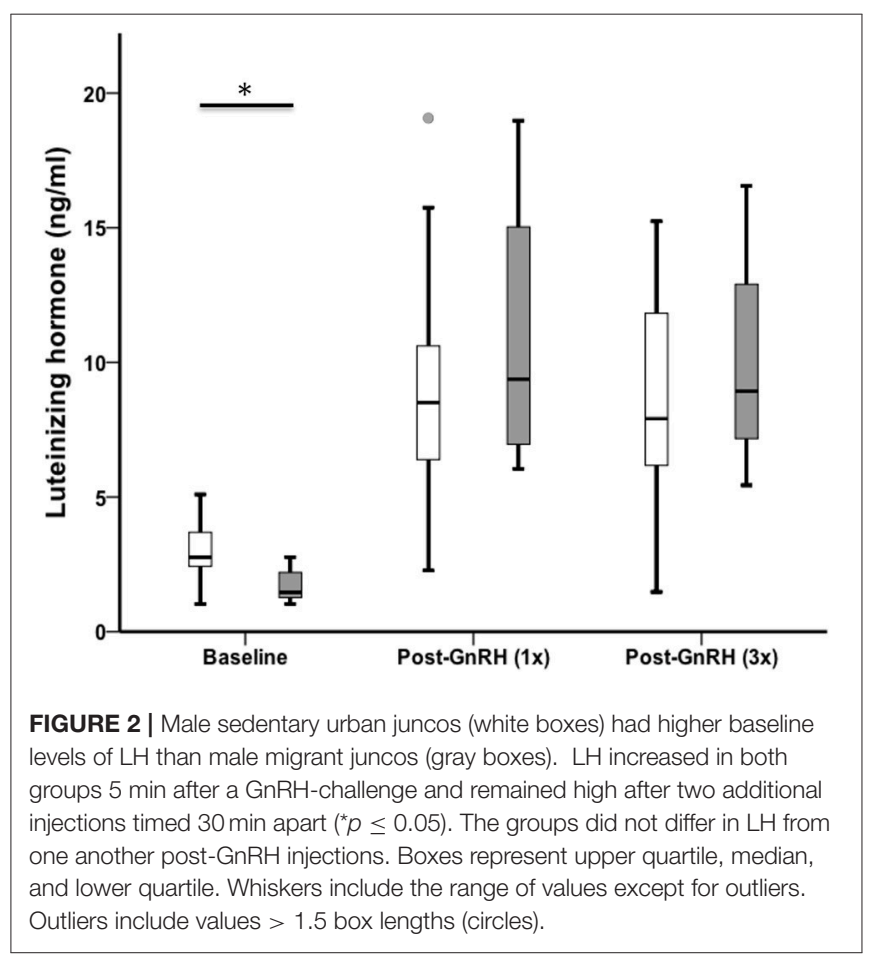




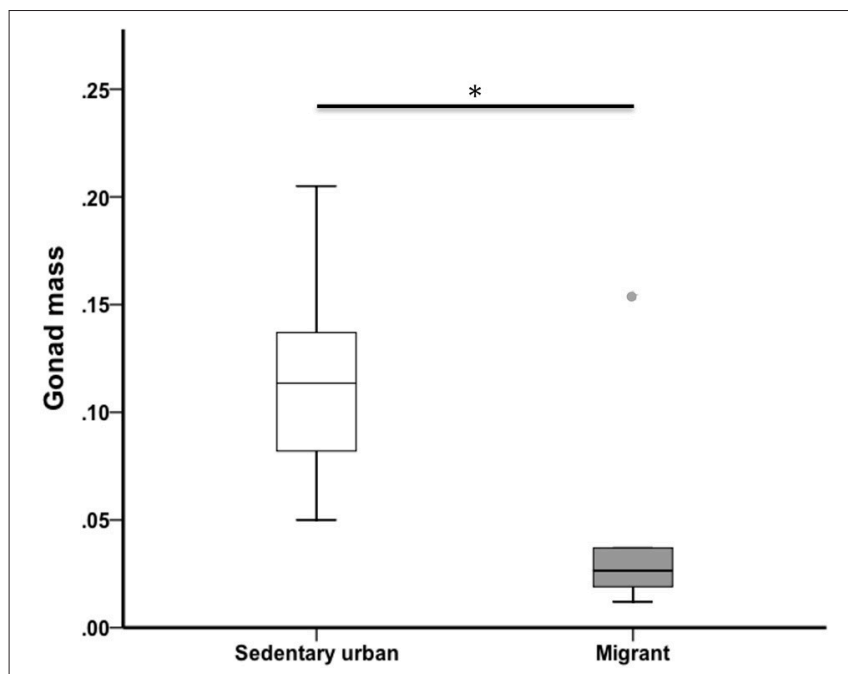

FIGURE 3 | Testis mass of male sedentary urban juncos was higher than that of migrant juncos in early spring. Boxes represent upper quartile, median, and lower quartile $\left({ }^{*} p \leq 0.05\right)$. Whiskers include the range of values except for outliers. Outliers include values $>1.5$ box lengths (circles).

19, $n_{\text {migrant }}=6, p=0.013$ ) (Figure 3). Median gonad mass was $0.113 \mathrm{~g}$ for sedentary urban juncos and $0.024 \mathrm{~g}$ for migrants.

\section{Cloacal Protuberance Volume}

Cloacal protuberance (CP) volume increased across the 4-week sampling period in all birds $\left(n=25\right.$, Chi-Square $\chi^{2}=35.10$, $\mathrm{df}=3, p<0.001$ ) however there was no difference when comparing sedentary urban and migrant juncos (CP week one: $U=56.50, n_{\text {urban }}=19, n_{\text {migrant }}=6, p=0.975$; CP week two: $U$ $=41.50, n_{\text {urban }}=19, n_{\text {migrant }}=6, p=0.324$; CP week three: $U=$ 55.50, $n_{\text {urban }}=19, n_{\text {migrant }}=6, p=0.924$; CP week $4: U=46.50$, $\left.n_{\text {urban }}=19, n_{\text {migrant }}=6, p=0.50\right)$.

\section{Testosterone}

Baseline testosterone increased across the 4-week sampling period in all birds $\left(n=23\right.$, Chi-Square $\chi^{2}=7.85$, df $=3, p$ $=0.049$; Figure 4A). Sedentary urban and migrant juncos had similar baseline testosterone during the first 2 weeks of the study (baseline $\mathrm{T}$ week one: $U=40.00, n_{\text {urban }}=19, n_{\text {migrant }}=6$, $p=0.279$; baseline T week two: $U=32.50, n_{\text {urban }}=18, n_{\text {migrant }}$ $=6, p=0.152$ ) but sedentary urban juncos had higher levels in weeks 3 and 4 (baseline T week three: $U=21.50, n_{\text {urban }}=18$, $n_{\text {migrant }}=6, p=0.030$; baseline $\mathrm{T}$ week $4: U=14.00, n_{\text {urban }}=$ $18, n_{\text {migrant }}=6, p=0.008$ ). Sedentary urban juncos had higher GnRH-induced testosterone than migrants throughout the study (GnRH T week one: $U=24.00, n_{\text {urban }}=19, n_{\text {migrant }}=6, p=$ 0.036; GnRH T week two: $U=19.00, n_{\text {urban }}=19, n_{\text {migrant }}=6, p$ $=0.016$; GnRH T week three: $U=19.00, n_{\text {urban }}=19, n_{\text {migrant }}=$ $6, p=0.016$; GnRH T week $4: U=19.00, n_{\text {urban }}=18, n_{\text {migrant }}=$ $6, p=0.020$; Figure 4B).

\section{CORT}

CORT increased across the 4-week sampling period in all birds $\left(n=21\right.$, Chi-Square $\chi^{2}=9.49, \mathrm{df}=3, p=0.023$; Figure 5A). Sedentary urban and migrant juncos had similar baseline CORT
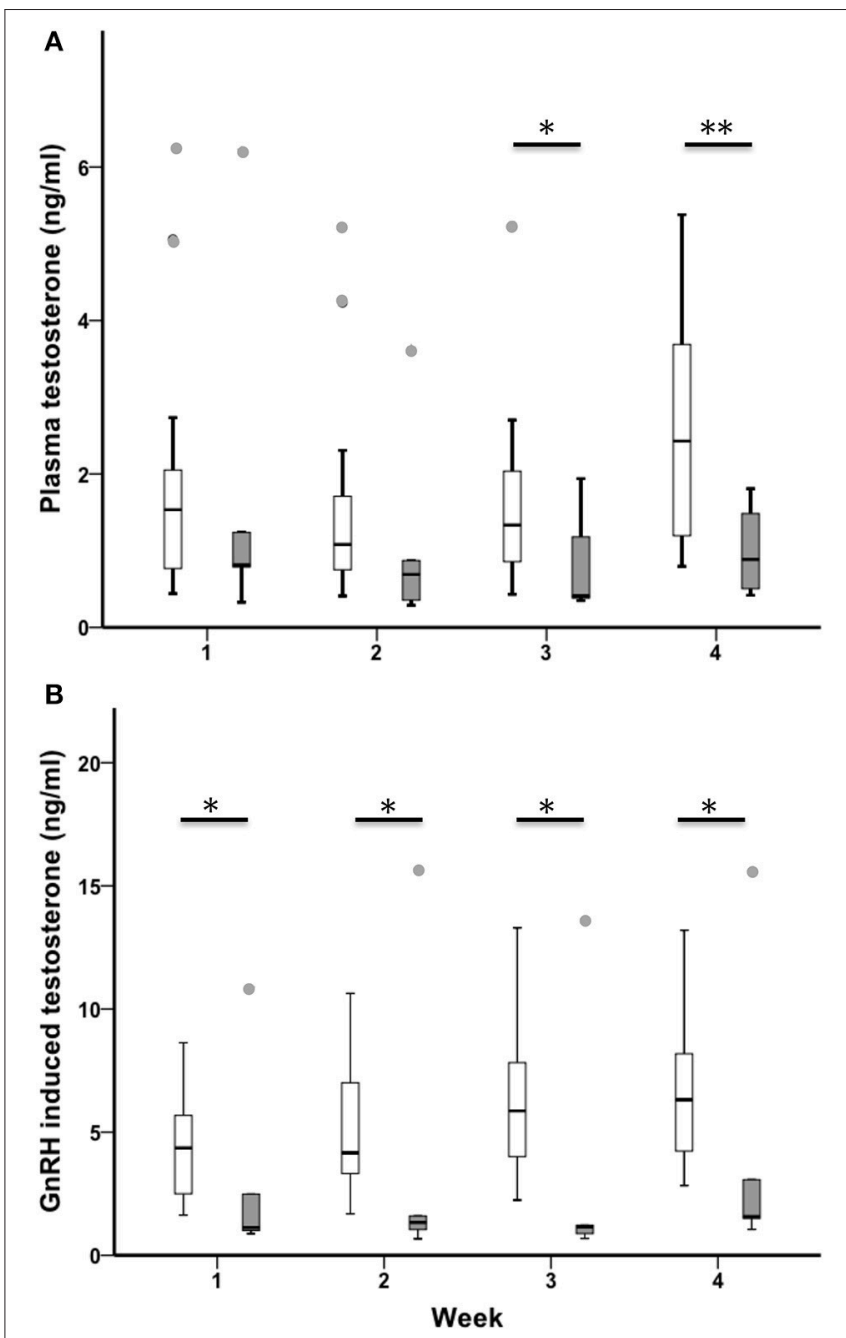

FIGURE 4 | Male sedentary urban juncos (white boxes) and migrant juncos (gray boxes) did not differ in plasma testosterone until the third week of sampling (12 \& 13 March) (A). Sedentary urban juncos had higher levels of testosterone in response to $\mathrm{GnRH}$-challenge $\mathbf{( B )}$ than migrant male juncos throughout the study $\left({ }^{\star} p \leq 0.05 ;{ }^{* *} p \leq 0.01\right)$. The samples were collected on the following dates: $1=26$ \& 27 February, $2=5 \& 6$ March, $3=12 \& 13$ March, $4=19 \& 20$ March. Boxes represent upper quartile, median, and lower quartile. Whiskers include the range of values except for outliers. Outliers include values $>1.5$ box lengths (circles).

in all 4 weeks of the study (CORT week one: $U=38.00, n_{\text {urban }}=$ $17, n_{\text {migrant }}=6, p=0.363$; CORT week two: $U=44.50, n_{\text {urban }}=$ $19, n_{\text {migrant }}=6, p=0.426$; CORT week three: $U=35.00, n_{\text {urban }}$ $=19, n_{\text {migrant }}=6, p=0.162$; CORT week $4: U=32.00, n_{\text {urban }}=$ $\left.16, n_{\text {migrant }}=6, p=0.238\right)$.

\section{Fat}

Migrants exhibited more subcutaneous fat than sedentary urban juncos throughout the study (Fat week one: $U=$ 13.00, $n_{\text {urban }}=19, n_{\text {migrant }}=6, p=0.002$; Fat week two: $U$ $=13.500, n_{\text {urban }}=19, n_{\text {migrant }}=6, p=0.003$; Fat week three: $U=20.50, n_{\text {urban }}=19, n_{\text {migrant }}=6, p=0.018$; Fat week 4 : $U=19.00, n_{\text {urban }}=19, n_{\text {migrant }}=6, p=0.004$; Figure $\left.5 \mathbf{B}\right)$. 

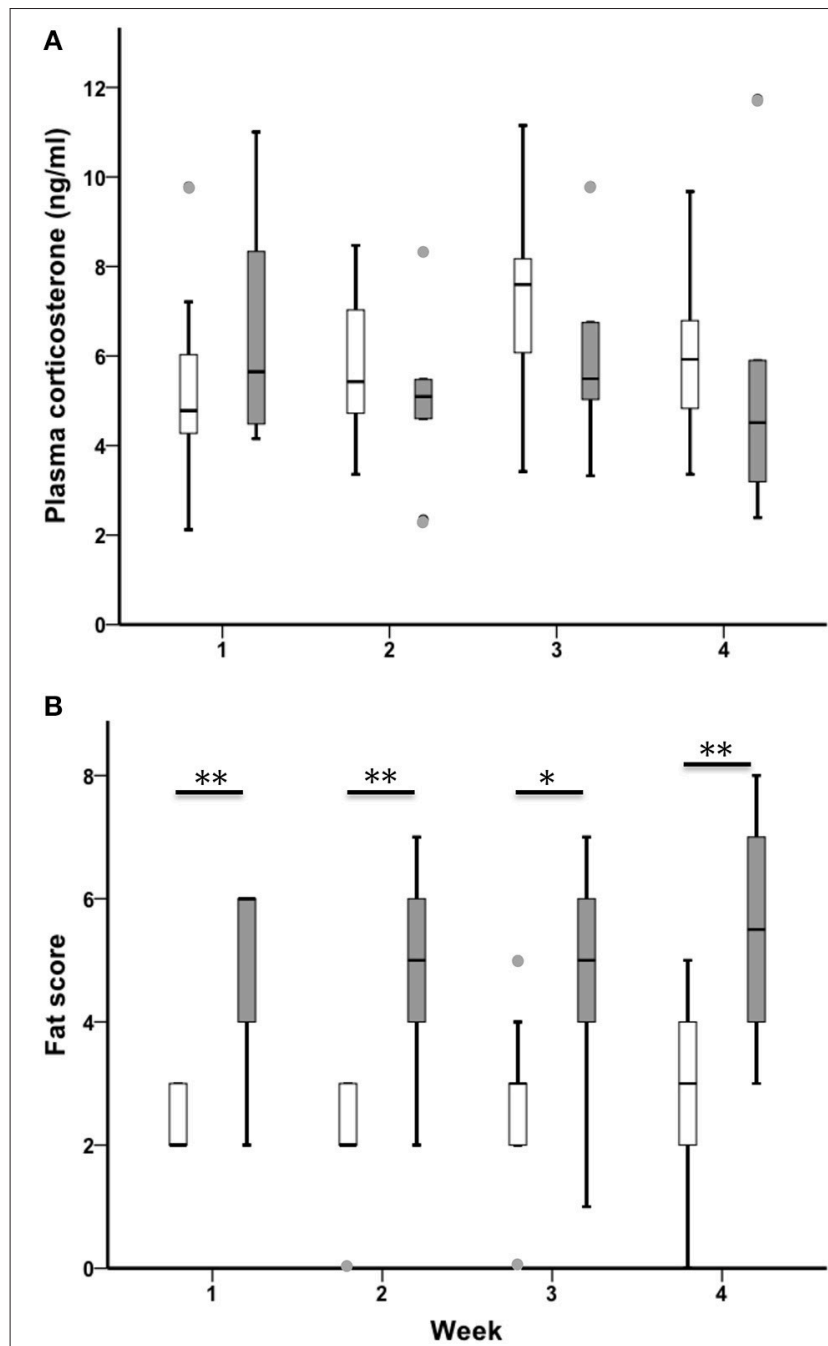

FIGURE 5 | Male sedentary urban juncos (white boxes) and migrant juncos (gray boxes) did not differ in plasma corticosterone at any point during the study (A). Male migrant juncos exhibited larger subcutaneous fat scores than urban male juncos (B) $\left({ }^{\star} p \leq 0.05 ;{ }^{* *} p \leq 0.01\right)$. The samples were collected on the following dates: $1=26 \& 27$ February, $2=5 \& 6$ March, $3=12 \& 13$

March, $4=19 \& 20$ March. Boxes represent upper quartile, median, and lower quartile. Whiskers include the range of values except for outliers. Outliers include values $>1.5$ box lengths (circles).

There was no difference in fat across the four sampling periods when sedentary and migratory juncos were combined $(n=25$, Chi-Square $\chi^{2}=2.97, \mathrm{df}=3, p=0.396$ ).

\section{LHR and FSHR}

At the end of the 4-week sampling period, there was no difference in gonad LH receptor or FSH receptor transcript abundance between sedentary urban and migrant juncos (LHR: $U=46.00$, $n_{\text {urban }}=18, n_{\text {migrant }}=6, p=0.594$; FSHR: $U=31.50, n_{\text {urban }}=$ $18, n_{\text {migrant }}=6, p=0.133$; Figure 6).

\section{GR and MR}

At the end of the 4-week sampling period, there was no difference in gonad glucocorticoid receptor or mineralocorticoid receptor
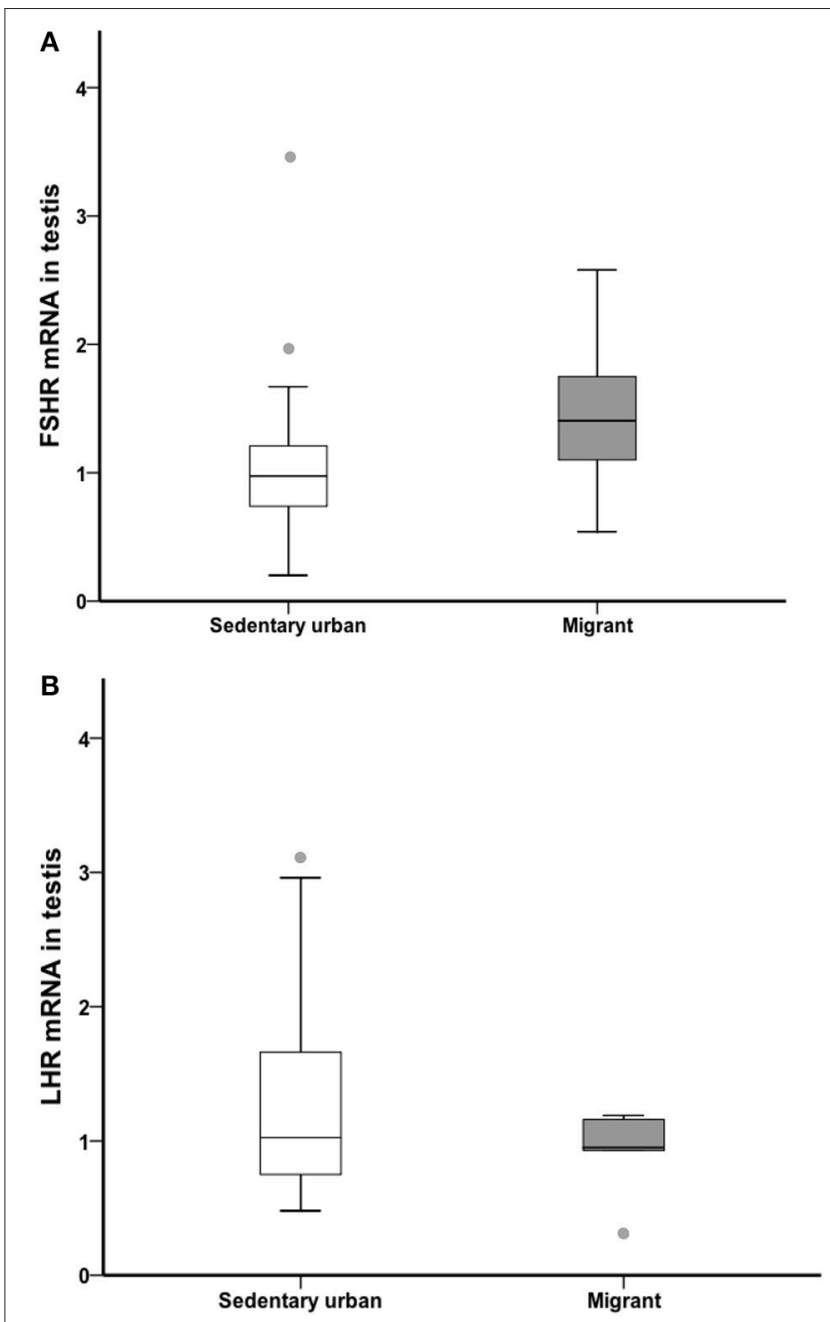

FIGURE 6 | Male sedentary urban juncos (white boxes) and male migrant juncos (gray boxes) did not differ in FSHR (A) or LHR (B) transcript abundance in the gonad. Measures of transcript abundance are $\log _{2}$-fold change relative to a calibrator. Boxes represent upper quartile, median, and lower quartile. Whiskers include the range of values except for outliers. Outliers include values $>1.5$ box lengths (circles).

transcript abundance between sedentary urban and migrant juncos (GR: $U=34.00, n_{\text {urban }}=18, n_{\text {migrant }}=6, p=0.182$; MR: $U=37.00, n_{\text {urban }}=18, n_{\text {migrant }}=6, p=0.257$; Figure 7$)$.

\section{DISCUSSION}

Findings from this study resemble those from other studies that have shown rapid advancement in the seasonal onset of reproduction in urban avian populations (Deviche and Davies, 2013). However, this study is unusual in the degree to which it addresses the physiological mechanisms that allow earlier reproduction in urban populations and the implications for genetic divergence over time because population differences were exhibited under identical environmental cues. 


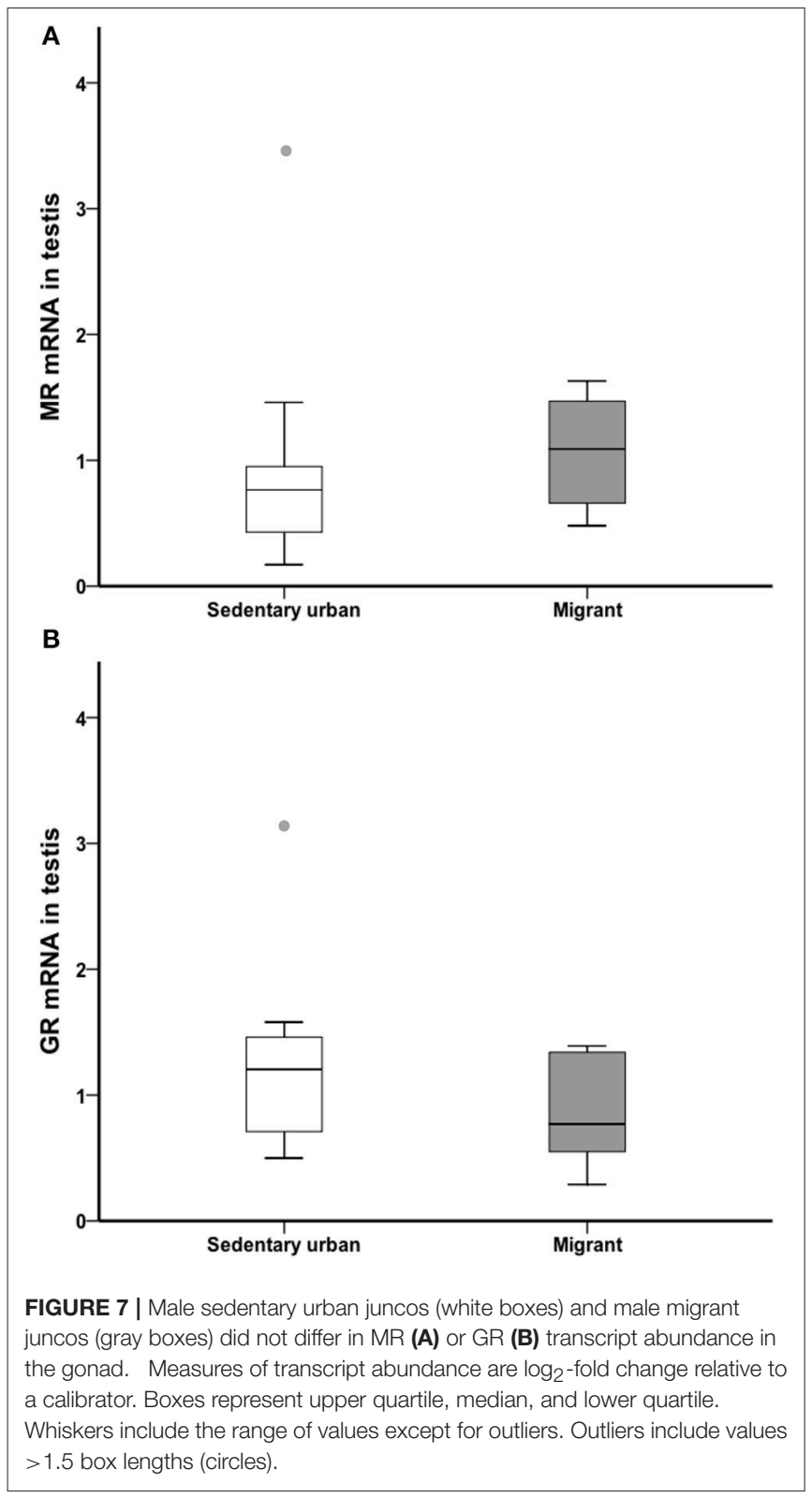

Timing of reproduction is critical to determining levels of gene flow between closely related populations and is subject to change as avian populations colonize rapidly expanding urban habitats. In this study, we compared indices of reproductive timing in two populations living in the same environment, a derived population that has recently become sedentary and begun to breed in San Diego CA and its ancestral relatives that co-exist with these urban colonists during winter but depart to breed elsewhere. By some but not all measures, reproductive development occurred earlier in the urban colonists. In the wild, baseline LH was greater in urban breeders but $\mathrm{LH}$ in response to $\mathrm{GnRH}$ did not differ between urban breeders and migrants (Figure 2). When birds from both populations were held in a common garden and exposed to the same simulated natural increases in day length with ample food, they nevertheless diverged in gonadal mass (Figure 3) and gonadal development as determined from testosterone release after stimulation by GnRH. Sedentary urban and migrant juncos were similar in baseline $\mathrm{T}$ until the third week of our sampling. However, throughout the sampling period, sedentary urban juncos elevated $\mathrm{T}$ more than migrant juncos, suggesting increased sensitivity at the level of the pituitary or the gonad (Figure 4). The populations did not differ in gonadal sensitivity to stimulation by LH or FSH when sensitivity was measured as abundance of transcripts for receptors for $\mathrm{LH}$ and FSH (Figure 6). The delay in reproductive timing in migrants is not likely due to suppression by the HPA axis because migrants did not differ from colonists in circulating levels of corticosterone (Figure 5A) or in the abundance of transcripts for gonadal glucocorticoid receptors (Figure 7). Whatever the mechanisms underlying differences in timing of reproductive development, they may help to explain divergence in recently separated and seasonally sympatric populations.

In combination, field $\mathrm{LH}$ and captive $\mathrm{T}$ results from our study suggest that differences in the timing of the seasonal increase in GnRH secretion could help explain differences in reproductive timing between sedentary urban and migrant juncos. While we found no difference between sedentary urban and migrant $\mathrm{LH}$ in response to $\mathrm{GnRH}$ (either $1 \mathrm{x}$ or $3 \mathrm{x}$ ), baseline LH and captive baseline T (weeks 3 and 4) were both higher in sedentary urban juncos, which suggests that $\mathrm{GnRH}$ secretion could increase seasonally earlier in sedentary urban juncos. In captivity, sedentary urban juncos also increased $\mathrm{T}$ more than migrants in response to $\mathrm{GnRH}$. In combination, these results suggest similar activity of the pituitary (no difference in $\mathrm{LH}$ after GnRH challenge) but earlier activation of hypothalamic and gonadal activity (higher baseline $\mathrm{LH}$ and $\mathrm{T}$ post-GnRH challenge). However, the underlying causes for these differences in seasonal activation are still unknown. The differences that we observed in the captive common-garden suggest a differential response between urban sedentary and migrant juncos to similar environmental cues. Urban sedentary juncos could be more sensitive than migrants to seasonal cues, such as photoperiod and food availability at the shared overwintering site and in the common-garden. As a result, the reproductive system of urban sedentary juncos could either respond earlier or develop at a faster rate in early spring.

Our finding of advanced seasonal elevation of baseline LH in sedentary urban juncos is similar to the results of a recent study that compared the seasonal timing of reproductive development in an urban population of Abert's Towhees (Melosone aberti) in Phoenix Arizona USA with that of a nearby rural population. Urban Abert's Towhees increased plasma LH, but not plasma testosterone, earlier than non-urban birds (Davies et al., 2015). In our captive common-garden, sedentary urban and migrant juncos also had similar plasma testosterone in the first 2 weeks of comparison, but diverged in the final 2 weeks of our study, with sedentary juncos displaying elevated baseline testosterone levels. Davies and colleagues suggest there has been a seasonal advancement in the endocrine activity of the anterior pituitary gland and/or hypothalamus in urban Abert's Towhees. Identifying and comparing the mechanistic basis for advances in the seasonal timing of reproduction in different species 
could be useful for identifying common mechanisms by which populations adapt to urban habitat.

At the conclusion of our captive study we also compared gonadal transcript abundance of LHR and FSHR in urban sedentary and migrant juncos. FSHR and LHR are important for seasonal gonadal growth, and LHR is critical to avian seasonal testosterone production (Vizcarra et al., 2015). Accordingly, we predicted higher FSHR and LHR transcript abundance in sedentary urban juncos in early spring. However, we did not find differences in transcript abundance of either FSHR or LHR (Figure 6). The absence of differences in gonadal LHR and FSHR transcripts, combined with elevated baseline LH observed from urban sedentary birds and elevated baseline testosterone during the final 2 weeks of our captive study, suggests that the earlier gonadal growth and responsiveness was not the result of a change in gonadal LH sensitivity to LH or FSH. Recent work has identified an inhibitory role of Gonadotropin Inhibitory Hormone $(\mathrm{GnIH})$ in the gonads of male songbirds (McGuire et al., 2013; Ernst et al., 2016). Future work is needed to identify whether decreased gonadal GnIH production and/or gonadal GnIH receptor abundance in sedentary urban juncos in early spring could be acting as a mechanism for earlier onset of reproduction. Another potential explanation for the variation that we observed in $\mathrm{T}$ production is that the populations could differ in expression of genes in the steroid biosynthetic pathway. A recent comparison of junco subspecies that differ in testosterone-mediated traits found variation in gonadal mRNA for key regulatory genes for testosterone production including StAR, CYP17, and p450scc (Rosvall et al., 2016).

Previous work has identified a relationship between plasma CORT and the activity of the reproductive system in birds (Schoech, 2009). Recent work on Rufous-winged Sparrows (Peucaea carpalis), a sedentary sparrow that breeds in arid habitat, reported reduced plasma $\mathrm{T}$ following stressors during pre-breeding and breeding (Deviche et al., 2014, 2016). However, plasma CORT and $\mathrm{T}$ were not found to be correlated at the individual level in Rufous-winged Sparrows, and there was no evidence for a functional relationship between elevated CORT and $\mathrm{T}$ levels.

In the current study, we evaluated whether either decreased plasma corticosterone and/or decreased gonadal receptors for corticosterone (GR and MR) might play a role in greater testosterone production in sedentary urban juncos in early spring. We compared circulating corticosterone and gonadal GR and MR transcript abundance in sedentary urban and migrant juncos in our common garden study. Both in the field and a common garden, sedentary urban juncos, and migrant juncos that breed close-by had similar baseline levels of corticosterone during the breeding season (Atwell et al., 2012). Similar to these observations, our data collected during the period preceding the breeding season found no differences in baseline levels of corticosterone; sedentary urban and migrant juncos had similar levels of corticosterone over our 4-week captive study in early spring (Figure 5A). Further, we also did not identify any differences in gonadal GR or MR transcript abundance in sedentary urban and migrant juncos (Figure 7). Thus, observations from the current study do not support a role for baseline glucocorticoids during the pre-breeding period in inhibiting reproductive development in migrant juncos overwintering with urban sedentary juncos.

Another possibility is that stress-induced levels of corticosterone might act to delay reproductive development in migrants. A previous study (Atwell et al., 2012) conducted during the breeding season, found higher stress-induced corticosterone in a nearby rural breeding population compared to breeders from the urban San Diego population. We did not measure stress-induced corticosterone in this study, so we cannot say whether differences in stress-induced corticosterone levels might have delayed reproductive development in migrant juncos in San Diego. However, we think that is unlikely because in a similar comparison in Virginia USA, migrant juncos captured during spring had lower, not higher, levels of stress-induced corticosterone as compared with seasonally sympatric residents (Bauer et al., 2016).

Fat varies seasonally in passerines in relation to transitions between wintering and migratory stages (Clark, 1979). Despite having access to the same amount of food in the common-garden environment, migrant juncos had more subcutaneous fat than sedentary urban juncos throughout early spring (Figure 5B). Beginning in late March, migrant juncos that overwinter in San Diego migrate to breeding sites prior to reproduction (Yeh and Price, 2004). Elevated fat reserves in migrant juncos in early spring likely serve as fuel for migration. Results from our captive comparison suggest this is a seasonal change that is not expressed in the sedentary urban colonists. Perhaps the absence of migration-related traits in the sedentary urban population allows them to respond to the favorable environmental conditions encountered in their newly urbanized habitat, facilitating earlier onset of reproduction.

\section{CONCLUSIONS}

Avian populations face novel challenges with ongoing global urbanization. By identifying the mechanistic underpinnings of adaptive traits associated with successful colonizations of urban areas, we will be better able to predict which populations will persist and adapt to rapidly changing environments. We have demonstrated differences between heteropatric sedentary urban and migrant juncos in the seasonal timing of gonadal responsiveness and upstream endocrine activity of the pituitary gland and hypothalamus. However, we found no differences between these recently diverged groups in expression of key genes associated with reproduction and sex steroid production in the gonads. Urbanization is an ongoing process and future studies should aim to identify the mechanisms responsible for advanced reproductive physiology in individuals colonizing urban habitats.

\section{AUTHOR CONTRIBUTIONS}

AF, TG, MA, JA, and EK, All contributed to the design of the experiments, collection of data, performance of lab work, and writing of the manuscript. SM and CS, Contributed to the design of the experiments, lab work, and writing of the manuscript. GF 
Contributed to design of the experiments, ran the GBS and DFA analyses, and contributed to writing the manuscript.

\section{ACKNOWLEDGMENTS}

We would like to thank Alexander Kauffman at UCSD for use of lab space and equipment and Tim Gentner at UCSD for serving as our representative to the IACUC. John McCormack and Brant Faircloth assisted with sequencing of the junco reference genome and provided support to GF. Jessica Graham, Emily Stewart, Katie Needham, Rachel Hanauer, Alex Hughes, Abby Kimmitt, Sam Slowinski, and Charli Taylor helped to collect and process samples. This work was funded

\section{REFERENCES}

Adriaensen, F., and Dhondt, A. A. (1990). Population dynamics and partial migration of the European robin (Erithacus rubecula) in different habitats. J. Anim. Ecol. 59, 1077-1090. doi: 10.2307/5033

Alberti, M., Correa, C., Marzluff, J. M., Hendry, A. P., Palkovacs, E. P., Gotanda, K. M., et al. (2017). Global urban signatures of phenotypic change in animal and plant populations. Proc. Natl. Acad. Sci. U.S.A. doi: 10.1073/pnas.16060 34114. [Epub ahead of print].

Atwell, J. W., Cardoso, G. C., Whittaker, D. J., Campbell-Nelson, S., Robertson, K. W., and Ketterson, E. D. (2012). Boldness behavior and stress physiology in a novel urban environment suggest rapid correlated evolutionary adaptation. Behav. Ecol. 23, 960-969. doi: 10.1093/beheco/ars059

Atwell, J. W., Cardoso, G. C., Whittaker, D. J., Price, T. D., and Ketterson, E. D. (2014). Hormonal, behavioral, and life-history traits exhibit correlated shifts in relation to population establishment in a novel environment. Am. Nat. 184, E147-E160. doi: 10.1086/678398

Bauer, C. M., Needham, K. B., Le, C. N., Stewart, E. C., Graham, J. L., Ketterson, E. D., et al. (2016). Hypothalamic-pituitary-adrenal axis activity is not elevated in a songbird (Junco hyemalis) preparing for migration. Gen. Comp. Endocrinol. 232, 60-66. doi: 10.1016/j.ygcen.2015.12.020

Bergeon Burns, C. M., Rosvall, K. A., Hahn, T. P., Demas, G. E., and Ketterson, E. D. (2014). Examining sources of variation in HPG axis function among individuals and populations of the dark-eyed junco. Horm. Behav. 65, 179-187. doi: 10.1016/j.yhbeh.2013.10.006

Blas, J. (2015). "Stress in birds," in Sturkie’s Avian Physiology, 6th Edn., ed C. Scanes (San Diego, CA: Academic Press), 769-810.

Bowen, G. J., Wassenaar, L. I., and Hobson, K. A. (2005). Global application of stable hydrogen and oxygen isotopes to wildlife forensics. Oecologia 143, 337-348. doi: 10.1007/s00442-004-1813-y

Chamberlain, D., Cannon, A., Toms, M., Leech, D., Hatchwell, B., and Gaston, K. (2009). Avian productivity in urban landscapes: a review and meta-analysis. Ibis 151, 1-18. doi: 10.1111/j.1474-919X.2008.00899.x

Clark, G. A. (1979). Body weights of birds: a review. Condor 81, 193-202. doi: $10.2307 / 1367288$

Danecek, P., Auton, A., Abecasis, G., Albers, C. A., Banks, E., DePristo, M. A., et al. (2011). The variant call format and VCFtools. Bioinformatics 27, 2156-2158. doi: 10.1093/bioinformatics/btr330

Davies, S., Behbahaninia, H., Giraudeau, M., Meddle, S. L., Waites, K., and Deviche, P. (2015). Advanced seasonal reproductive development in a male urban bird is reflected in earlier plasma luteinizing hormone rise but not energetic status. Gen. Comp. Endocrinol. 224, 1-10. doi: 10.1016/j.ygcen.2015.05.005

Dawson, A. (2015). Annual gonadal cycles in birds: modeling the effects of photoperiod on seasonal changes in GnRH-1 secretion. Front. Neuroendocrinol. 37, 52-64. doi: 10.1016/j.yfrne.2014.08.004

Deviche, P., and Davies, S. (2013). "Reproductive phenology of urban birds: environmental cues and mechanisms," in Avian Urban Ecology: Behavioural and Physiological Adaptations, eds D. Gil and H. Brumm (Oxford: Oxford University Press), 98-115. by the National Science Foundation (IOS-1257474 to EK and IOS-1257527 to TG). SM acknowledges Roslin Institute strategic grant funding from the Biotechnology and Biological Sciences Research Council (BB/J004316/1 and BB/J004332/1). Any use of trade, product, or firm names is for descriptive purposes only and does not imply endorsement by the U.S. Government.

\section{SUPPLEMENTARY MATERIAL}

The Supplementary Material for this article can be found online at: http://journal.frontiersin.org/article/10.3389/fevo. 2017.00085/full\#supplementary-material

Deviche, P., Beouche-Helias, B., Davies, S., Gao, S., Lane, S., and Valle, S. (2014). Regulation of plasma testosterone, corticosterone, and metabolites in response to stress, reproductive stage, and social challenges in a desert male songbird. Gen. Comp. Endocrinol. 203, 120-131. doi: 10.1016/j.ygcen.2014. 01.010

Deviche, P., Valle, S., Gao, S., Davies, S., Bittner, S., and Carpentier, E. (2016). The seasonal glucocorticoid response of male Rufous-winged Sparrows to acute stress correlates with changes in plasma uric acid, but neither glucose nor testosterone. Gen. Comp. Endocrinol. 235, 78-88. doi: 10.1016/j.ygcen.2016.06.011

Deviche, P., Wingfield, J. C., and Sharp, P. J. (2000). Year-class differences in the reproductive system, plasma prolactin and corticosterone concentrations, and onset of prebasic molt in male dark-eyed juncos (Junco hyemalis) during the breeding period. Gen. Comp. Endocrinol. 118, 425-435. doi: $10.1006 /$ gcen.2000.7478

Elshire, R. J., Glaubitz, J. C., Sun, Q., Poland, J. A., Kawamoto, K., Buckler, E. S., et al. (2011). A robust, simple genotyping-by-sequencing (GBS) approach for high diversity species. PLoS ONE 6:e19379. doi: 10.1371/journal.pone.0019379

Ernst, D. K., Lynn, S. E., and Bentley, G. E. (2016). Differential response of GnIH in the brain and gonads following acute stress in a songbird. Gen. Comp. Endocrinol. 227, 51-57. doi: 10.1016/j.ygcen.2015.05.016

Evans, K. L., Hatchwell, B. J., Parnell, M., and Gaston, K. J. (2010). A conceptual framework for the colonisation of urban areas: the blackbird Turdus merula as a case study. Biol. Rev. 85, 643-667. doi: 10.1111/j.1469-185x.2010.00121.x

Foll, M., and Gaggiotti, O. (2008). A genome-scan method to identify selected loci appropriate for both dominant and codominant markers: a bayesian perspective. Genetics 180, 977-993. doi: 10.1534/genetics.108.092221

Fudickar, A. M., Greives, T. J., Atwell, J. W., Stricker, C. A., Ketterson, E. D., Williams, T. D., et al. (2016a). Reproductive allochrony in seasonally sympatric populations maintained by differential response to photoperiod: implications for population divergence and response to climate change. Am. Nat. 187, 436-446. doi: 10.1086/685296

Fudickar, A. M., Peterson, M. P., Greives, T. J., Atwell, J. W., Bridge, E. S., and Ketterson, E. D. (2016b). Differential gene expression in seasonal sympatry: mechanisms involved in diverging life histories. Biol. Lett. 12:20160069. doi: 10.1098/rsbl.2016.0069

Greives, T. J., Fudickar, A. M., Atwell, J. W., Meddle, S. L., and Ketterson, E. D. (2016). Early spring sex differences in luteinizing hormone response to gonadotropin releasing hormone in co-occurring resident and migrant dark-eyed juncos (Junco hyemalis). Gen. Comp. Endocrinol. 236, 17-23. doi: 10.1016/j.ygcen.2016.06.031

Hahn, T., Pereyra, M., Katti, M., Ward, G., and MacDougall-Shackleton, S. (2005). "Effects of food availability on the reproductive system," in Functional Avian Endocrinology, eds A. Dawson and P. J. Sharp (New Delhi: Narosa Publishing House), 167-180.

Jawor, J. M., McGlothlin, J. W., Casto, J. M., Greives, T. J., Snajdr, E. A., Bentley, G. E., et al. (2006). Seasonal and individual variation in response to GnRH challenge in male dark-eyed juncos (Junco hyemalis). Gen. Comp. Endocrinol. 149, 182-189. doi: 10.1016/j.ygcen.2006.05.013 
Jenni, L., and Jenni-Eiermann, S. (1998). Fuel supply and metabolic constraints in migrating birds. J. Avian Biol. 29, 521-528. doi: 10.2307/36 77171

Ketterson, E. D., Fudickar, A. M., Atwell, J. W., and Greives, T. J. (2015). Seasonal timing and population divergence: when to breed, when to migrate. Curr. Opin. Behav. Sci. 6, 50-58. doi: 10.1016/j.cobeha.2015.09.001

Li, H., and Durbin, R. (2009). Fast and accurate short read alignment with Burrows-Wheeler transform. Bioinformatics 25, 1754-1760. doi: 10.1093/bioinformatics/btp324

Marzluff, J. M. (2016). A decadal review of urban ornithology and a prospectus for the future. Ibis 159, 1-13.doi: 10.1111/ibi.12430

McGuire, N. L., Koh, A., and Bentley, G. E. (2013). The direct response of the gonads to cues of stress in a temperate songbird species is season-dependent. PeerJ 1:e139. doi: 10.7717/peerj.139

McKenna, A., Hanna, M., Banks, E., Sivachenko, A., Cibulskis, K., Kernytsky, A., et al. (2010). The genome analysis toolkit: a mapreduce framework for analyzing next-generation DNA sequencing data. Genome Res. 20, 1297-1303. doi: $10.1101 /$ gr. 107524.110

Meddle, S. L., Romero, L. M., Astheimer, L. B., Buttemer, W. A., Moore, I. T., and Wingfield, J. C. (2002). Steroid hormone interrelationships with territorial aggression in an arctic-breeding songbird, Gambel's whitecrowned sparrow, Zonotrichia leucophrys gambelii. Horm. Behav. 42, 212-221. doi: 10.1006/hbeh.2002.1813

Nolan, V. (2002). Dark-Eyed Junco: Junco Hyemalis. Birds of North America. Ithaca: Incorporated.

Partecke, J., and Gwinner, E. (2007). Increased sedentariness in European Blackbirds following urbanization: a consequence of local adaptation? Ecology 88, 882-890. doi: 10.1890/06-1105

Partecke, J., Schwabl, I., and Gwinner, E. (2006). Stress and the city: urbanization and its effects on the stress physiology in European blackbirds. Ecology 87, 1945-1952. doi: 10.1890/0012-9658(2006)87[1945:SATCUA]2.0.CO;2

Partecke, J., Van't Hof, T., and Gwinner, E. (2004). Differences in the timing of reproduction between urban and forest European blackbirds (Turdus merula): result of phenotypic flexibility or genetic differences? Proc. R. Soc. Lond. B Biol. Sci. 271, 1995-2001. doi: 10.1098/rspb.20 04.2821

Pritchard, J. K., Stephens, M., and Donnelly, P. (2000). Inference of population structure using multilocus genotype data. Genetics 155, 945-959.

R_Core_Team (2015). R: A Language and Environment for Statistical Computing. Vienna: R Foundation for Statistical Computing.

Ramenofsky, M., Campion, A. W., Pérez, J. H., Krause, J. S., and Németh, Z. (2017). Behavioral and physiological traits of migrant and resident whitecrowned sparrows: a common garden approach. J. Exp. Biol. 220, 1330-1340. doi: $10.1242 /$ jeb.148171

Rasner, C., Yeh, P., Eggert, L., Hunt, K., Woodruff, D., and Price, T. (2004). Genetic and morphological evolution following a founder event in the dark-eyed junco, Junco hyemalis thurberi. Mol. Ecol. 13, 671-681. doi: 10.1046/j.1365-294X.2004.02104.x

Rosvall, K. A., Burns, C. M. B., Jayaratna, S. P., and Ketterson, E. D. (2016). Divergence along the gonadal steroidogenic pathway: implications for hormone-mediated phenotypic evolution. Horm. Behav. 84, 1-8. doi: 10.1016/j.yhbeh.2016.05.015

Schaper, S. V., Dawson, A., Sharp, P. J., Gienapp, P., Caro, S. P., and Visser, M. E. (2012). Increasing temperature, not mean temperature, is a cue for avian timing of reproduction. Am. Nat. 179, E55-E69. doi: 10.1086/6 63675

Schmieder, R., and Edwards, R. (2011). Quality control and preprocessing of metagenomic datasets. Bioinformatics 27, 863-864. doi: 10.1093/bioinformatics/btr026

Schoech, S. J. (2009). Food supplementation experiments: a tool to reveal mechanisms that mediate timing of reproduction. Integr. Comp. Biol. 49, 480-492. doi: $10.1093 / \mathrm{icb} / \mathrm{icp} 005$
Shanahan, D. F., Strohbach, M. W., Warren, P. S., and Fuller, R. A. (2014). "The challenges of urban living," in Avian Urban Ecology, eds D. Gil and H. Brumm (Oxford: Oxford University Press), 3-20.

Sharp, P., Dunn, I., and Talbot, R. (1987). Sex differences in the LH responses to chicken LHRH-I and-II in the domestic fowl. J. Endocrinol. 115, 323-331. doi: $10.1677 /$ joe. 0.1150323

Unitt, P. (2005). "San Diego County Bird Atlas," in Proceedings of the San Diego Natural History Museum Number 39 (Temucula, CA: Ibis).

Vizcarra, J., Alan, R., and Kirby, J. (2015). "Chapter 29 - Reproduction in male Birds A2," in Sturkie's Avian Physiology, 6th Edn., ed C. G. Scanes (San Diego, CA: Academic Press), 667-693.

Wassenaar, L., and Hobson, K. (2003). Comparative equilibration and online technique for determination of non-exchangeable hydrogen of keratins for use in animal migration studies. Isotopes Environ. Health Stud. 39, 211-217. doi: 10.1080/1025601031000096781

Watts, H. E., MacDougall-Shackleton, S. A., and Hahn, T. P. (2015). Variation among individuals in photoperiod responses: effects of breeding schedule, photoperiod, and age-related photoperiodic experience in birds. J. Exp. Zool. A Ecol. Genet. Physiol. 323, 368-374. doi: 10.1002/jez.1929

Wingfield, J. C., Crim, J. W., Matfocks, P. W., and Farner, D. S. (1979). Responses of photosensitive and photorefractory male white-crowned sparrows (Zonotrichia leucophrys gambelii) to synthetic mammalian luteinizing hormone releasing hormone (Syn-LHRH). Biol. Reprod. 21, 801-806. doi: 10.1095/biolreprod21.4.801

Wingfield, J. C., Sullivan, K., Jaxion-Harm, J., and Meddle, S. L. (2012). The presence of water influences reproductive function in the song sparrow (Melospiza melodia morphna). Gen. Comp. Endocrinol. 178, 485-493. doi: 10.1016/j.ygcen.2012.07.007

Winker, K. (2010). On the origin of species through heteropatric differentiation: a review and a model of speciation in migratory animals. Ornithol. Monogr. 69, 1-30. doi: 10.1525/om.2010.69.1.1

Wolfson, A. (1952). The cloacal protuberance: a means for determining breeding condition in live male passerines. Bird Banding 23, 159-165. doi: $10.2307 / 4510381$

Wunder, M. B., Jehl, J. R., and Stricker, C. A. (2012). The early bird gets the shrimp: confronting assumptions of isotopic equilibrium and homogeneity in a wild bird population. J. Anim. Ecol. 81, 1223-1232. doi: 10.1111/j.1365-2656.2012.01998.x

Yeh, P. J. (2004). Rapid evolution of a sexually selected trait following population establishment in a novel habitat. Evolution 58, 166-174. doi: 10.1111/j.0014-3820.2004.tb01583.x

Yeh, P. J., and Price, T. D. (2004). Adaptive phenotypic plasticity and the successful colonization of a novel environment. Am. Nat. 164, 531-542. doi: $10.1086 / 423825$

Zheng, X. (2012). SNPRelate: Parrallel Computing Toolset for Genome-Wide Association Studies. R package version 95.

Zinzow-Kramer, W. M., Horton, B. M., and Maney, D. L. (2014). Evaluation of reference genes for quantitative real-time PCR in the brain, pituitary, and gonads of songbirds. Horm. Behav. 66, 267-275. doi: 10.1016/j.yhbeh.2014.04.011

Conflict of Interest Statement: The authors declare that the research was conducted in the absence of any commercial or financial relationships that could be construed as a potential conflict of interest.

Copyright $\odot 2017$ Fudickar, Greives, Abolins-Abols, Atwell, Meddle, Friis, Stricker and Ketterson. This is an open-access article distributed under the terms of the Creative Commons Attribution License (CC BY). The use, distribution or reproduction in other forums is permitted, provided the original author(s) or licensor are credited and that the original publication in this journal is cited, in accordance with accepted academic practice. No use, distribution or reproduction is permitted which does not comply with these terms. 